\title{
Need-driven dementia-compromised behavior: An alternative view of disruptive behavior
}

\author{
Donna L. Algase, PhD, RN \\ Cornelia Beck, PhD, RN, FAAN \\ Ann Kolanowski, PhD, RN \\ Ann Whall, PhD, RN, FAAN \\ Stanley Berent, PhD \\ Kathy Richards, PhD, RN \\ Elizabeth Beattie, MA, RN
}

\begin{abstract}
The disruptive behavior of persons with dementia is a problem of considerable clinical interest and growing scientific concern. This paper offers a view of these behaviors as expressions of unmet needs or goals and provides a comprehensive conceptual framework to guide further research and clinical practice. Empirical findings and clinical impressions related to wandering, vocalizations and aggression to support and illustrate the framework are presented.
\end{abstract}

\section{Introduction}

Disruptive behaviors displayed by demented elderly often result in nursing home placement ${ }^{1}$ and challenge the skills of even the best-trained nursing personnel. Despite increasing attention from researchers to behaviors such as wandering, vocalizations and aggression, efforts to explain these phenom-

Donna L. Algase, PhD, RN, Associate Professor, School of Nursing, University of Michigan; Faculty Associate, Institute of Gerontology, University of Michigan Medical Center, Ann Arbor, Michigan.

Cornelia Beck, PhD, RN, FAAN, Associate Dean for Research and Evaluation, University of Arkansas for Medical Sciences, Little Rock, Arkansas.

Ann Kolanowski, PhD, RN, Professor and Chair, Department of Nursing, Wilkes University, Wilkes Barre, Pennsylvania.

Ann Whall, PhD, RN, FAAN, Professor, School of Nursing and Associate Director of the Geriatric Center, University of Michigan, Ann Arbor, Michigan.

Stanley Berent, PhD, Professor and Head of Psychology and Neurology, University of Michigan, School of Medicine, Ann Arbor, Michigan.

Kathy Richards, PhD, RN, Assistant Professor, University of Arkansas for Medical Sciences, Little Rock, Arkansas.

Elizabeth Beattie, MA, RN, Senior Lecturer, Department of Nursing Sciences, James Cook University, Townsville, Queensland, Australia. ena remain incomplete. Based on empirical works and clinical experience, we propose a framework from which to study these behaviors by considering their purpose or meaning to persons who display them. Within this view, wandering, vocalizations and aggression represent each of the three categories of disruptive behavior identified by Cohen-Mansfield and associates. Empirical works and clinical impressions supporting the framework are reviewed. Finally, wandering, vocalization and aggression serve as examples for application to clinical practice and research.

Disruptive behavior is a term that reflects the caregiver's view more than the cognitively-impaired $(\mathrm{Cl})$ person's perspective in a situation. While behaviors such as wandering or repetitive questioning may interfere with or disrupt clinical care routines, they may actually express or embody the CI person's goal or needs. ${ }^{2}$ Seen this way, these behaviors become meaningful and therefore, potentially useful in directing nursing care. Researchers can use this framework to better identify CI persons at greatest risk and to isolate those needs with highest likelihood of precipitating these behaviors. From such knowledge, researchers can develop and test targeted intervention strategies for these need-driven, dementia-compromised behaviors (NDB).

Within our framework, depicted in Figure 1, we believe NDBs arise in pursuit of a goal or as expression of a need. As such, NDBs reflect the interaction of salient background and proximal factors found within either CI persons or their immediate environment or both. Although disruptive, dysfunctional, or ineffective from an objective stance, NDBs constitute the most integrated and meaningful response possible, given limitations imposed by a dementing condition, strengths preserved from the person's basic abilities and personality, and 


\section{Manny Acosta Needed Money}

\section{as Much as He Needed Medicine}

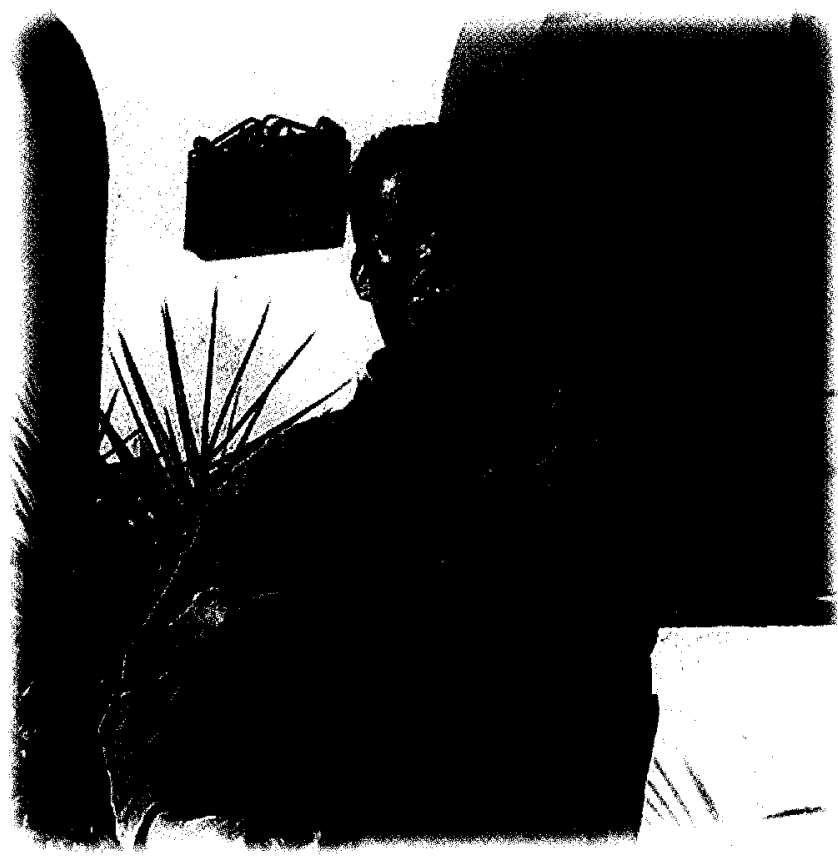

A life-threatening illness such as cancer, Alzheimers disease or AIDS can create devastating financial problews for your patients. In addition to medical bills, there are mortgage and car payments, college tuition bills, credit card charges and other expenses.

As a healthcare professional, you should know about Viaticus. Our service allows individuals facing a life-threatening illness to sell their life insurance policy for cash, unlocking a significant financial resource they can use to improve the quality of their lives today. Thanks to Viaticus, Manny Acosta can now focus on fulfilling the goals he had before he became ill.

For more information about this important new service or to learn about our educational programs for healthcare professionals and their patients, please contact Viaticus toll free at 1-888-383-7824. 
Figure 1. Factors affecting NDB

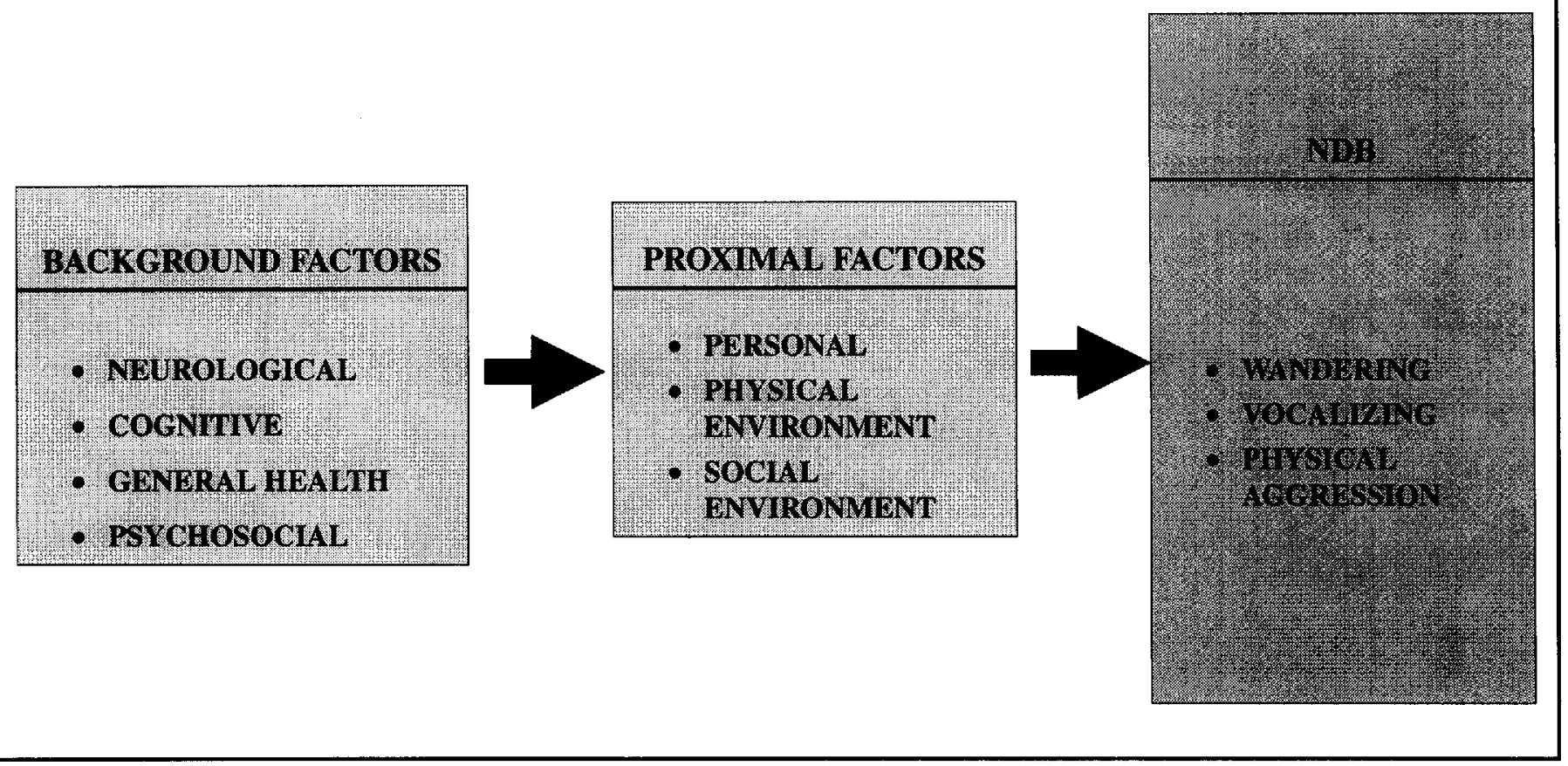

constraints, challenges, or supports offered by the immediate environment.

Background factors thought to operate in producing NDBs include the somewhat stable neurological, cognitive, health status, as well as psychosocial factors. Proximal factors are the more fluid or fluctuating aspects of the immediate physical and social environment and the dynamic or changing needs and states within the CI person. Proximal factors are likely to precipitate NDBs.

According to our literature review, some background and proximal variables may operate across a range of NDBs, while others affect only a specific behavior, such as wandering. Figure 2 lists variables thought pertinent to multiple NDBs, as well as those considered important to wandering, vocalization and aggression. Investigation of background factors can lead to the development of risk profiles for NDBs. By isolating relevant proximal factors, a promising set of ideas for developing general and specific nursing interventions for NDBs can result. However, this framework, while more comprehensive than other efforts to explain disruptive behaviors, needs validation and refinement for overall and specific NDBs, such as wandering, vocalization and aggression.

\section{Wandering}

Locomotion can range from the speed and endurance of a long distance runner to the ability to bear weight and maintain balance in a frail elder. One's wayfinding ability involves a destination (goal), a route (series of mental operations or deci- sion points), and physical ability to move through space. In dementia, wandering might reflect diminished wayfinding ability in pursuit of a need or goal. A cognitive change, such as an attention deficit, might interfere with one's ability to keep a goal or destination in mind. Similarly, a lifetime preference for motion as a stress reducer, might induce walking, even without a destination. ${ }^{3,4}$ Likewise, physical aspects of an environment, such as noise or bright lights, might grasp one's attention or curiosity and thus, draw a person toward them, while certain social aspects, such as crowding, may induce fear or discomfort, and thus, repel a person. Wandering may reflect a variety of needs or goals under varying personal and environmental circumstances. Information about the relationship between these goals, needs, environmental conditions and particular rhythms and patterns of wandering, will provide the foundation for designing and targeting effective interventions.

\section{Vocalizations}

Communicating one's needs may entail an extensive discussion or a simple gesture, such as pointing. Communication involves a felt need, one's awareness of the need, and the ability (verbal or non-verbal) to make the need known to others. In dementia, disruptive vocalizations may represent lessened ability to communicate. Memory loss may cause residents to forget that they have expressed a need or that it has been met, resulting in repeated questions. Similarly, noisy behavior may represent an effort to fulfill a need for sensory stimulation. Likewise, when physical conditions are unpleasant, such as during a cold 
Figure 2. Background and proximal factors affecting NDC behavior

\begin{tabular}{|c|c|c|}
\hline \multicolumn{3}{|c|}{ General } \\
\hline Bachervand & Proximal & ND Behamior \\
\hline \multirow{3}{*}{\begin{tabular}{l}
\multicolumn{1}{c}{ Neurological factors } \\
Specific regional brain involvement \\
Neurotransmitter imbalance \\
Circadian rhythm deterioration \\
Motor ability \\
\end{tabular}} & Don an lo fota & \multirow[b]{2}{*}{ Dimension } \\
\hline & Personal ractors & \\
\hline & $\begin{array}{l}\text { Emotions } \\
\text { Physiological need states } \\
\text { Functional performance }\end{array}$ & \multirow[t]{6}{*}{$\begin{array}{l}\text { Frequency } \\
\text { Duration }\end{array}$} \\
\hline Cognitive factors & Physical environment & \\
\hline \multirow{2}{*}{$\begin{array}{l}\text { Attention } \\
\text { Memory } \\
\text { Visuo-spatial ability } \\
\text { Language skills }\end{array}$} & $\begin{array}{l}\text { Light level } \\
\text { Noise level } \\
\text { Temperature } \\
\end{array}$ & \\
\hline & Social environment & \\
\hline Health status & \multirow{2}{*}{$\begin{array}{l}\text { Ward ambience } \\
\text { Staff stability } \\
\text { Staff mix }\end{array}$} & \\
\hline $\begin{array}{l}\text { General health } \\
\text { Functional ability } \\
\text { Affective state } \\
\end{array}$ & & \\
\hline \multirow{4}{*}{$\begin{array}{l}\quad \text { Psychosocial factors } \\
\text { Gender } \\
\text { Education } \\
\text { Occupation } \\
\text { Personality type } \\
\text { History of psychosocial stress } \\
\text { Behavioral response to stress }\end{array}$} & SPECME & \multirow[b]{2}{*}{$\begin{array}{l}\text { AWDDERTC } \\
\text { Pattern } \\
\text { Percent cycle locomoting } \\
\text { 24-hour distribution }\end{array}$} \\
\hline & $\begin{array}{l}\text { Level of social engagement } \\
\text { Complexity of design } \\
\text { Crowding }\end{array}$ & \\
\hline & $\begin{array}{l}\text { Match of assistance to ability } \\
\text { Presence of others }\end{array}$ & $\begin{array}{l}\text { Type } \\
\text { Pitch } \\
\text { Volume } \\
\text { Interval } \\
\text { 24-hour distribution }\end{array}$ \\
\hline & $\begin{array}{l}\text { Room size } \\
\text { Speed of caregiving } \\
\text { Staff burnout } \\
\text { Caregiver demeanor and banter }\end{array}$ & $\begin{array}{l}\text { Type } \\
\text { Care procedure }\end{array}$ \\
\hline
\end{tabular}

shower, vocalization may serve as a means of drawing attention to the discomfort of a situation.

\section{Aggression}

When CI persons can no longer meet their needs or goals, they may become aggressive to deal with the resulting frustration. Thus, aggression might reflect diminished ability to deal with frustration or ambiguity. Some neuropsychological changes such as disinhibition, may interfere with their ability to selfregulate or execute behavior independent of environmental influences. ${ }^{5} \mathrm{~A}$ person with a hostile premorbid personality may become more aggressive as damage to the cortex results in disinhibition of these tendencies. Likewise, inappropriate assistance with activities of daily living (ADLs) may threaten personal abilities, obstruct goal-directed activity and lead to aggression.

\section{Background factors affecting NDB}

\section{Neurological factors}

Ongoing studies of neurological factors in $\mathrm{CI}$ individuals may help clarify brain-behavior relationships in $\mathrm{AD}$ and other dementias. A connection between NDBs and neurological fac- 
tors has been documented in studies examining regional brain damage, neurotransmitter imbalances, circadian rhythm disturbances and motor ability.

\section{Regional CNS damage}

Damage to certain regions of the central nervous system (CNS) may contribute to NDB. However, areas of reduced brain function vary greatly in dementia. Recent longitudinal studies using positron emission tomography (PET) scans have shown increased right/left metabolic asymmetry in patients with Alzheimer's disease (AD) ${ }^{6,7}$ Lateralized defects and areas of reduced cerebral glucose metabolism correspond to some language and visuospatial impairments. In a sample of 33 patients with $A D$, four metabolic sub-groups emerged using principal components analysis. The prevalence of NDB differed among the subgroups. ${ }^{8}$

Some NDBs may result from a particular region of brain damage. Wanderers performed more poorly on tests of parietal lobe functioning than did CI controls. ${ }^{9,10}$ In a study of 27 consecutive $\mathrm{AD}$ patients with recent PET scans, reduced left-sided brain function appeared to induce anxiety-tension $(r=.33)$ and hostility $(r=.52) .{ }^{11}$ Agitation, inappropriate behavior, and personality change corresponded with reduced cerebral glucose metabolism in CI subjects with paralimbic deficits $(n=8) .{ }^{8}$

\section{Neurotransmitters}

In $\mathrm{AD}$, cholinergic, nonadrenergic, and serotonergic innervation of the cerebral cortex showed degeneration on postmortem examination. ${ }^{12}$ Another postmortem study, documented reductions in serotonin and 5-hydroxyindoleacetic acid (5HIAA) in the superior frontal and inferior temporal lobes, fusiform gyri, and temporal lobe 17 institutionalized demented subjects when compared with 18 matched controls. ${ }^{13}$

Increased locomotor activity and restlessness of wandering behavior may stem from a relative excess of dopamine, as compared to acetylcholine in $\mathrm{AD}$ victims. ${ }^{14}$ While no direct evidence links neurotransmitters with wandering or disruptive vocalizations, they are likely involved in aggressive behavior. In 26 nondemented persons with various personality disorders, low concentrations of 5-HIAA, a serotonin metabolite in human cerebral spinal fluid, corresponded with increased aggression $(r=-.78) .{ }^{15}$ Low levels of 5-HIAA in adulthood corresponded with a history of deviant and suicidal behavior in childhood. ${ }^{16-18}$ Together, these findings implicate decreased serotonin in the brain as a basis for impulsive behavior. ${ }^{19}$ Aggressive behavior in some patients with $\mathrm{AD}$ may be related to loss of serotonin.

\section{Circadian circuitry}

The hypothalamic suprachiasmatic nucleus, associated with information processing and rhythm generation, shows a decrease in size and number of cells releasing vasopressin in subjects over 80-years old and an even greater decrease in those with $\mathrm{AD} .{ }^{20} \mathrm{~A}$ disturbed circadian distribution of locomotor activity has been documented in $\mathrm{AD}^{21}$ and in wanderers. ${ }^{22} \mathrm{An}$ end-of-day pattern in agitation and seasonal variation in sundowning suggest involvement of the circadian system. ${ }^{23}$

\section{Motor ability}

Ability to wash one's face, maintain balance while turning, and tie shoelaces differentiated functional level among three groups of nursing home residents (independent, requiring assistance, and dependent), ${ }^{24}$ many of whom are $\mathrm{Cl}$. Inability to walk unassisted can predict urinary incontinence in $\mathrm{CI}$ nursing home residents. ${ }^{25}$ Motor ability may likewise affect NDB. For example, loss of motor ability necessary to ambulate or to propel a wheelchair effectively eliminates wandering. In fact, efforts at restraint or limiting mobility are based upon this logic. Poor motor ability possibly plays a role in verbally disruptive behavior or aggression. Immobility can limit one's ability to satisfy their personal needs and may result in vocalization, frustration and aggression.

\section{Cognitive factors}

\section{Basic cognitive skills (attention and memory)}

The number of NDBs significantly increases with greater cognitive impairment. ${ }^{26,27}$ A sample of autopsy-confirmed $A D$ patients $(n=28)$ showed a significant progressive relationship between cognitive deficits, behavioral impairments and poor performance on the Haycox Dementia Behavior scale. ${ }^{28}$ However, the frequency of NDB declines in late stage dementia. ${ }^{29}$

Few studies have correlated specific neurocognitive deficits with particular disruptive behaviors. Wanderers have higher levels of global cognitive impairment. ${ }^{9,30}$ Wandering also may result from spatial disorientation, visuoconstructive deficits, ${ }^{31}$ or poor abstract thinking, spatial, and judgment skills. ${ }^{9}$ As dementia progresses, agitated and aggressive behaviors also increase. ${ }^{32-36}$ Resistive behavior during bathing corresponds highly, but indirectly, with memory, attention and visuospatial deficits. ${ }^{37}$

\section{Perceptual and sensory skills}

People with AD experience problems in color vision, depth perception, eye movements, contrast sensitivity and higher order visual perception. ${ }^{38}$ Heminopsia and other visual field losses likewise occur with strokes. Odor recognition, identification, and memory, have also been reported. ${ }^{39,40}$

Limited indirect evidence suggests that these sensory alterations may influence NDB. Stripes in various patterns placed upon the floor in front of doorways and various camouflage techniques applied to doors and their opening mechanisms resulted in fewer attempted exits by wanderers. ${ }^{41,42}$ Clinical evidence also suggests that wanderers move more often to locations within their immediate line of vision as opposed to those located further away.

\section{Language}

A range of altered speech and language skills, such as word 
finding deficiencies and paraphrasias, occurs in dementia. Language alterations may relate to NDB to the degree that they inhibit effective communication.

Algase $^{9}$ demonstrated that language skills best differentiated wanderers from nonwanderers who were better able to read, follow directions and name objects. Language deficits also may relate to resistive behavior during bathing. ${ }^{37}$ To effectively deal with frustration or threat, the individual must autoarticulate thoughts, feelings, and goals, a function of the left hemisphere language system. In turn, the individual must plan and evaluate behavior and its effect on the physical and social world, a function of the frontal lobe. Damage to these regions may result in an inability to use inner speech to modulate behavior ${ }^{43}$ and may account for dysfunctional vocalizations as well.

\section{Health status}

\section{General health}

Little research has examined relationships between general health status or specific health conditions and behavioral issues in dementia. In one study, CI patients with more physical problems, such as cardiovascular disease and surgery, exhibited verbally agitated behaviors while those with fewer diagnoses displayed physically non-aggressive behaviors (e.g., wandering). ${ }^{44}$ Limited clinical evidence also links cardiovascular disease to nocturnal wandering, ${ }^{45}$ urinary tract infections to aggression ${ }^{46}$ and infection to vocalizations. ${ }^{47,48}$

\section{Functional ability}

Researchers have demonstrated a direct relationship between the extent of cognitive impairment and decline in both ADL and instrumental ADL (IADL). ${ }^{49,50}$ While we can extrapolate some of this knowledge to explain NDB, relationships remain unclear. Higher levels of functional ability may enable CI persons to partially satisfy their needs and goals, thus reducing NDBs. Conversely, lower levels of functional ability may hamper personal need satisfaction and result in wandering, vocalization or aggression.

\section{Affect}

Clinical impressions and limited empirical evidence support an association of certain persistent affective states and behavior in dementia. Anxiety may induce screaming. ${ }^{51}$ Presence and severity of depression significantly predicted functional status. ${ }^{52}$ Likewise, depression and screaming are connected. ${ }^{44}$ However, no relationship appeared to exist between depression and wandering in the same study.

\section{Psychosocial factors}

\section{Demographics}

Researchers have studied gender, age, education, and other demographic factors as risks for AD and vascular dementia, but the connection between these variables and behaviors in de- mentia has received scant attention. A large nursing home survey $(\mathrm{N}=3,351)$ detected no gender difference for wandering behavior, ${ }^{26}$ even though men and women generally differ in spatial abilities. Subjects who displayed physically non-aggressive behavior tended to be younger, i.e., 75-80 years old. Women engaged in more noisiness ( 10.7 percent vs 8 percent), while males were more abusive ( 16.8 percent vs. 10.1 percent). An association may exist between occupational roles and certain types of wandering behavior. 4

\section{Personality, stress, and behavioral responses to stress}

Personality, the dynamic organization of psychophysiological systems within the person determines the person's unique pattern of adjustment to the environment. ${ }^{53}$ One criterion used to diagnose dementia is personality change. ${ }^{54}$ Personality and life events may be salient to NDB.

Recent studies of personality in AD illustrate a significant change in major domains as judged by caregivers when asked to compare premorbid and present personality of mild to moderately demented patients. ${ }^{55-58}$ Extraversion and conscientiousness decreased while neuroticism increased. However, assessed by correlating premorbid and current scores, a person's position in the sample remained relatively constant (range of r's = .67-.79).

No one has specifically studied the personality of wanderers or verbally agitated $\mathrm{CI}$ persons. However, according to Dawson and Reid, ${ }^{59}$ wanderers tended to have an intact social facade. Chart audits of the social history of eight institutionalized wanderers indicated that wandering may be related to lifelong patterns of coping with stress. ${ }^{4}$ In a comparison of premorbid psychosocial patterns among wanderers and nonwanderers, family members recalled wanderers as having engaged in higher levels of social and leisure activities $(t=3.36, p=.003)$, experienced more stressful life events $(t=4.88, \mathrm{p}=.000)$, shown a motoric reaction to stress $(t=6.79, \mathrm{p}=.000)$, and demonstrated a more motoric behavioral style $(\mathrm{t}=5.69, \mathrm{p}=$ $.000) .{ }^{3}$ Of 408 nursing home residents, those who engaged in physically non-aggressive behaviors (e.g., pacing, wandering) were more likely to have been separated from spouse $(t=4.05$, $\mathrm{p}<.01)$, had financial problems $(\mathrm{t}=2.38, \mathrm{p}<.05)$, survived a life-threatening experience $(\mathrm{t}=3.61, \mathrm{p}<.01)$, or immigrated $(\mathrm{t}$ $=3.09, \mathrm{p}<.01$ ) (3). ). In related work, nursing home residents exposed to a life-threatening experience $(\mathrm{N}=154)$ screamed significantly more than unexposed residents $(\mathrm{N}=168 ; \mathrm{t}(322)$ $=1.98, \mathrm{p}<.05)(44)$. Though personality does not account entirely for life events, it may be a deciding element in one's choices. In a four-year longitudinal study $(\mathrm{N}=83)$, extraversion predisposed one to positive events $(r=.24 . p<.05)$ and neuroticism to negative ones $(r=.23, p<.05){ }^{67}$

In a sample of 38 subjects, Chatterjee and associates ${ }^{55}$ found that caregivers recalled $\mathrm{AD}$ patients with paranoid delusions as having been more hostile (partial $r=.42$ ). Further, studies of demented persons have linked premorbid personality to depres- 
sion $^{60,61}$ and aggression. ${ }^{62-64}$ Those who displayed aggressive behavior were more likely to have had financial problems $(t=$ $2.43, \mathrm{p}<.05){ }^{32}$

\section{Proximal factors affecting NDB: Personal factors}

\section{Emotions}

From a clinical perspective, wandering may be "agenda" behavior, arising from intermittent feelings of anxiety, frustration, or boredom. ${ }^{2}$ Even cognitively intact persons scream or strike out when afraid. While clinical observations such as these are prevalent, no one has systematically evaluated them.

\section{Physiological need states}

A variety of need states, such as fatigue, pain, or hunger, may produce NDB. The most evidence for a link between physiological states and these behaviors exists with sleep. A number of studies have shown more sleep disruption in demented patients than in age-matched controls. Dementia patients typically experience lowered sleep efficiency, higher percentage of stage one sleep, and greater frequency of arousals and awakenings. ${ }^{68}$ Sleep efficiency and number of awakenings correlated with severity of dementia. ${ }^{69-71}$ Further, the incidence of sleep-related respiratory disturbance (SRRD) is greater in the elderly ${ }^{72-74}$ and is associated with frequent nocturnal awakenings. However, researchers have conflicting data on whether demented persons display higher levels of SRRD than do aged controls. ${ }^{75,76}$

Wandering may stem from frequent nocturnal awakening, whether caused by staff ${ }^{44}$ or SRRD. ${ }^{23}$ Verbally-agitated behaviors likewise relate to fewer hours of sleep ${ }^{44}$ and more reported pain. ${ }^{32}$ However, the relationships should be viewed with caution because nursing staff measured sleep pattern and pain retrospectively. By disturbing nighttime sleep, staff can increase aggression in residents during the day. ${ }^{32}$ Anxiety and hostility also are associated with SRRD. ${ }^{23}$ Experience has shown that a bath, attempted when a CI person is tired, may induce resistance, aggression, or screaming.

\section{Functional performance}

As discussed earlier, high or low functional ability may predispose some CI persons to various NDBs by sustaining or limiting their ability to pursue personal needs or goals. However, functional performance may fall short of actual functional ability. ${ }^{77}$ Created when caregivers impose unnecessary constraints or overdo for the CI person, this excess disability or forced dependency may produce NDB as a rebound phenomenon. ${ }^{78}$

\section{Physical environment}

The physical environment is the overall setting including its layout, design, and routines. It also includes light, noise, and temperature. Both a macro and micro view may be important for modulating NDB. An environment designed to reduce stimulation and pace activities to residents' tolerances can reduce catastrophic reactions. ${ }^{79}$ Institutional routines such as bed checks and linen changes correspond with sundowning ${ }^{80}$ and increased aggressive behavior. ${ }^{32}$ On a micro-level, exposure to bright light therapy can reduce restlessness and agitation $^{81}$ and improve sleep in CI persons. ${ }^{82}$ Our clinical observations also suggest that noise and high levels of activity in confined spaces can increase wandering and vocalizations, perhaps by overwhelming residents' attentional or cognitive capacity or by inducing anxiety.

\section{Social environment}

The social environment encompasses social contacts, personal network and caregivers. Both wandering ${ }^{4}$ and screaming $^{83}$ are associated with greater time alone. The overall level of agitated behaviors is related to a lack of intimacy in the social network ${ }^{83,84}$ Disruptive behaviors occur more frequently with primarily unlicensed personnel who lack adequate preparation for reducing environmental demands. ${ }^{85}$

Some dimensions of an environment have both physical and social properties. For example, legibility (the immediacy with which one can comprehend or understand an environment) is reflected in clear and consistent physical characteristics (e.g., floor plans, seating arrangements) and social conventions (e.g., staffing and programming). On a macro-level, a highly legible environment may help reduce NDBs. ${ }^{86}$ On a micro-level, the warmth of an environment may lessen aggression during showers or baths. A comfortable room temperature together with a caregiver's inviting demeanor create an atmosphere inconsistent with aggressive outbursts. While offering great potential as a source of intervention, the impact of social and physical environment, upon disruptive behaviors has received little conceptual development or empirical study.

\section{Applications to practice and research}

Our proposed framework offers one perspective for organizing and integrating relevant empirical findings and clinical impressions to deal with the complex issue of disruptive behavior in dementia. While we cannot manipulate some elements of the model, particularly background factors, knowledge of these can provide direction in identifying those at risk and suggesting how to specifically modify the environment for those exhibiting a particular behavior. Narrower models provide more limited guidance and do not allow for the confounding effects of other variables. Using a narrower framework, for example, we can predict the pattern of cognitive impairment by discovering metabolic asymmetries. Accordingly, a greater degree of language, rather than visuospatial difficulties, usually accompanies left-sided hypometabolism. Thus, affected individuals may respond better to gestures than verbal communication. With a comprehensive framework, we can combine knowledge of this pattern of impairment with that of other possible risk factors and situational precipitants to identify individuals at highest 
risk. Thus, development of more targeted strategies for use with particular individuals or clinical subgroups under various sets of identifiable environmental circumstances can proceed.

Further, we can refine our framework to apply to a specific NDB. By using the framework to organize research findings pertinent to one behavior, we can highlight important directions for research and practice. In figure 2, for example, we have extracted variables specific to NDBs presented in this paper and organized them into working sets of proximal factors. Accordingly, nurses in a clinical setting attempting to modify wandering for a given $\mathrm{Cl}$ person might increase social interaction. Researchers interested in clarifying the neuropsychological basis of wandering might compare wandering output, pattern, and distribution while controlling for level of social engagement, crowding and complexity of physical design. Guided by the framework, those developing interventions might examine effects of various kinds and degrees of environmental cueing for effect on amount and pattern of wandering.

Similarly, we can apply concepts and their relationships salient to vocalizations. For example, persons who are spending much of their time alone because their social environment provides little opportunity for interaction may shout or repeat words or phrases as a means of stimulation. Providing a talking book may decrease vocalizations by providing stimulation. Likewise, the pain of a urinary tract infection may be causing a patient to scream when toileted. By observing the timing and frequency of vocalizations, clinicians can obtain clues about the cause of it. Researchers might explore the neuropsychological basis of vocalizations by examining relationships between language skills, memory loss, and various types of vocalizations while controlling for important environmental factors.

Finally, we can approach the study of aggression from this framework. Accordingly, clinicians might prevent or ameliorate aggression by encouraging caregivers to respect personal space and to interact in a relaxed and warm manner. Researchers might explore the role of sleep pattern or the introduction of natural elements into the environment in affecting aggression in late-stage dementia. This comprehensive framework provides a view of behavioral issues in dementia with the potential to advance humane care and the science that should undergird it. When cast as expressions of unmet needs or goals arising in the context of relevant background and proximal factors, behaviors of $\mathrm{CI}$ persons may eventually become better understood and managed.

\section{References}

1. Sanford JRA: Tolerance of disability in elderly dependents by supporters at home: Its significance for hospital practice. British Medical Journal. 1975; 3 (471-473).

2. Rader J, Doan J, Schwab M: How to decrease wandering, a form of agenda behavior. Geriatric Nursing. 1985; 6 (4),196-199.

3. Monsour N, Robb S: Wandering behavior in old age: A psychosocial study. Social Work. 1982; 27, 411-416.

4. Snyder L, Rupprecht P, Pyrek J, Brekhaus S, Moss T: Wandering.
The Gerontologist. 1978; 18(3), 272-280.

5. Lhermitte F: Human anatomy and the frontal lobes. Part II: Patient behavior in complex and social situations: The "Environmental Dependency Syndrome." Annals of Neurology. 1986; 19, 335-343.

6. Grady C, Haxby J, Schlageter N, Berg G, Rapoport S: Stability of metabolic and neurospychological asymmetries in dementia of the Alzheimer type. Neurology. 1986; 36, 1390-1392.

7. Haxby J, Grady C, Koss E, Horwitz B, Heston L, Schapiro M, Friedland R, Rapoport S: Longitudinal study of cerebral metabolic asymmetries and associated neuropsychological patterns in early dementia of the Alzheimer's type. Archives of Neurology. 1990; 47, 753-760.

8. Grady C, Haxby J, Shapiro M, Gonzales-Aviles A, Kumar A, Ball M, Heston L, Rapoport S: Subgroups in dementia of the Alzheimer's type identified using positron emission tomography. Journal of Neuropsychiatry and Clinical Neuroscience. 1990; 2, 373-384.

9. Algase DL: Cognitive discriminants of wandering among nursing home residents. Nursing Research. 1992; 41(2), 78-81.

10. deLeon M, Potegal M, Gurland B: Wandering and parietal signs in senile dementia of Alzheimer's type. Neuropsychobiology. 1984; $11,155-157$.

11. Knesper D, Giordani B, Koeppe R, Kuhl D: Does cerebral metabolic asymmetry predict emotions? Presented at the Fifth Annual Albert $\mathbf{J}$. Silverman Research Conference. 1994; University of Michigan.

12. Crow T, Cross A, Cooper S, Deakin J, Ferrier I, Johnson J, Joseph M, Owen F, Poulter M, Lofthouse R, Corsellis J, Chambers D, Blessed G, Perry E, Perty R, Tomlinson B: Neurotransmitter receptors and monoamine metabolites in the brains of patients with Alzheimer-type dementia and depression and suicides. Neuropharmocology. 1984; 23(12B), 1561-1569.

13. Palmer A, Stratman G, Proctor A, Bowen D: Possible neurotransmitter basis of behavioral changes in Alzheimer's disease. Annals of Neurology. 1988; 28, 616-620.

14. Weller M: A biochemical hypothesis of wandering. Medical Science Law. 1987; 27(1), 40-41.

15. Brown G, Goodwin F, Ballenger J, Goyer P, Major L: Aggression in humans correlates with cerebral-spinal fluid amine metabolites. Psychiatry Research. 1979; 1, 131-139.

16. Brown G, Klein W, Goyer P, Minichiello M, Kreusi M, Goodwin F: Relationship of childhood characteristics to cerebrospinal fluid 5-hydroxyindoleacetic acid in aggressive adults. In C. Shagass (Ed.), Proceedings of the IV World Congress of Biological Psychiatry. (pp. 177-179). 1986. Philadelphia: Elsevier.

17. Virkkunen M, Rawlings $R$, Tokola $R$, Poland R, Guidotti A, Nermeroff C, Bissette G, Kalogeras K, Karonen S, Linnoila M: CSF biochemistries, glucose metabolism and diurnal activity rhythms in alcoholic violent offenders, fire setters and healthy volunteers. Archives of General Psychiatry. 1994; 51, 20-27.

18. Neelsen D, Goldman D, Virkkunen M, Tokola R, Rawlings R, Linnoila M: Suicidality and 5-hydroxyndoleacetic acid concentration associates with tryptophan hydoxylase polymorphism. Archives of General Psychiatry. 1994; 51, 34-38.

19. Apter D, vonPraag H, Plutchnik R, Sevy S, Korn M, Brown S: Interrelationships among anxiety, aggression, impulsivity, and mood; A serotonergically linked cluster? Psychiatry Research. 1990; 32, 191-199.

20. Swaab DF, Fliers E, Partiman TS: The suprachiasmic nucleus of the human brain in relation to sex and senile dementia. Brain Research. $1985 ; 342(1), 37-44$.

21. Satlin A, Volicer L, Ross V, Herz L, Campbell S: Bright light treatment of behavioral and sleep disturbances in patients with Alzheimer's disease. American Journal of Psychiatry. 1992; 149(8), 102832.

22. Algase DL, Beel-Bates C, Kupferschmid B: Wandering rhythms 
and patterns of cognitively-impaired elderly. Journal of Nursing Measurement. In press.

23. Bliwise DL: Dementia. In N.H. Kryger, T. Roth,\& W.C. Dement. Principles and Practice of Sleep Medicine. (2nd ed ) 1994. Philadelphia W B. Saunders.

24. Glick O, Swanson EA: Motor performance correlates of functional dependence in long-term care residents. Nursing Research. 1995; 44(1), 4-8.

25. Jirovec $M$, Wells $T$ : Urinary incontinence in nursing home residents with dementia: The mobility-cognition paradigm. Applied Nursing Research. 1990; 3, 112-117.

26. Jackson ME, Drugovich ML, Fretwell MD, Spector WD, Sternberg J, Rosenstein RB: Prevalence and correlates of disruptive behavior in the nursing home. Journal of Aging and Health. 1989; 1(3),349369.

27. Teri L, Larson E, Reifler B: Behavioral disturbance in dementia of the Alzheimer's type. Journal of the American Geriatrics Society. $1988 ; 36,1-6$.

28. Kurita A, Blass J, Nolan K, Block R, Thaler H: Relationship between cognitive status and behavioral symptoms in Alzheimer's disease and mixed dementia. Journal of the American Geriatrics Society. 1993; 41(7), 732-736.

29. Reisberg B, Franssen E, Scain SG: Stage-specific incidence of potentially remediable behavioral symptoms in aging and Alzheimer's disease. Bulletin of Clinical Neurosciences. 1989; 54(95-112).

30. Martino-Saltzman D, Blasch B, Morris R, McNeal L: Travel behavior of nursing home residents perceived as wanderers and nonwanderers. Gerontologist. 1991; 11, 666-672.

31. Henderson VW, Mack W, Williams BW: Spatial disorientation in Alzheimer's disease. Archives of Neurology. 1989; 46, 391-394.

32. Cohen-Mansfield J, Marx M, Rosenthal A: A description of agitation in a nursing home. Journal of Gerontology. 1989; 44(3), M-77-84.

33. Cohen-Mansfield J, Billig N, Lipson A, Rosenthal AS, Pawlson L: Medical correlates of agitation in nursing home residents. Gerontology. 1990b; 36 (3), 150-158.

34. Rubin E, Morris J, Berg L: The progression of personality changes in senile dementia of the Alzheimer's type. Journal of the American Geriatrics Society. 1987; 35, 721-790.

35. Swearer J, Drachman D, O'Donnell B, Mitchell A: Troublesome and disruptive behaviors in dementia. Journal of the American Geriatrics Society. 1988; 36, 784-790.

36. Winger J, Schirm V, Stewart D: Aggressive behavior in long-term care. Journal of Psychosocial Nursing. 1987; 25, 28-33.

37. Whall AL, Black AM, Yankou D, Groh C: (1994) Addressing aggressive behavior in demented nursing home residents. Paper presented at the Alzheimer's Disease Conference, sponsored by The University of Michigan, MADRC and Munson Medical Center, 9122194, Ann Arbor, MI.

38. Mendez MF, Mendez MA, Martin R, Smythe KA, Whitehouse PJ: Complex visual disturbance in Alzheimer's disease. Neurology. 1990; $40(3 \mathrm{P}+1), 439-443$

39. Doty RL, Reyes PF, Gregor T: Presence of both odor and identification and detection deficits in Alzheimer's disease. Brain Research Bulletin. 1987; 18(5), 597-600.

40. Moberg PJ, Pearlson GD, Speedie LJ, Lipsey JR, Strauss ME, Folstein SE: Olfactory recognition and differential impairments in early and late Huntington's and Alzheimer's diseases. Journal of Clinical and Experimental Neuropsychology. 1987; 9(6), 650-654.

41. Hussain RA, Brown DC: Use of two dimensional grid patterns to limit hazardous ambulation in demented patients. Journal of Gerontology. 1987; 29 (5), 558-560.

42. Namazi K, Rosner T, Calkins M: Visual barriers to prevent ambulatory Alzheimer's patients from exiting through an emergency door.
The Gerontologist. 1989; 29 (5), 699-702.

43. Miller L: Neuropsychology of the aggressive psychopath: An integrative review. Aggressive Behavior. 1987; 13. (119-140). 44. Cohen-Mansfield J, Marx M: Do past experiences predict agitation in nursing home residents? International Journal of Human Development. 1990a; 28 (4), 285-294.

45. Cameron DE: Studies in senile nocturnal delirium. Psychiatric Quarterly. 1941; 15(1), 47-53.

46. Malone ML, Thompson L, Goodwin JS: Aggressive behavior in the institutionalized elderly. Journal of the American Geriatrics Society. 1993; 41 (8), 853-856.

47. Cohen-Mansfield J, Werner P: Vocally disruptive behavior in elderly persons: A review. In B.J. Vellas., J.L. Abarede. \& P.J. Garry (Eds.) Facts and Research in Gerontology (Supplemental Dementia and Cognitive Functioning). pp 73-82. 1994. New York: Springer.

48. Warne MA, Ryden MB, Feldt KS: Experience of pain in cognitively impaired elders. The Gerontologist. 1994; 34 (Special Issue 1), 150-156.

49. Bassett SS, Folstein MF: (1991). Cognitive impairment and functional disability in the absence of psychiatric diagnosis. Psychological Medicine. 21, 77-84.

51. Hallberg IR, Norberg A: (1990). Staffs interpretation of the experience behind vocally disruptive behavior in severely demented patients and their feelings about it. An exploratory study. International Journal of Aging and Human Development. 31(4), 295-305.

52. Fitz AG, Ten L: Depression, cognition and functional ability of patients with Alzheimer's disease. Journal of the American Geriatrics Society. 1994; 42(2), 186-191.

53. Allport G: Personality: A psychological interpretation. 1937. New York: Holt.

54. American Psychiatric Association, Nomenclature and Statistics. (1987). Diagnostic and Statistical Manual of Mental Disorders. (3rd ed. revised). (pp. 103-107). Washington DC: American Psychiatric Association.

55. Chaterjee A, Strauss M, Smyth K, Whitehouse P: Personality changes in Alzheimer's disease. Archives of Neurology. 1992; 49, 486-491.

56. Richman M: Stability of personality traits in the demented elderly. (Doctoral dissertation, Hofstra University, 1989). Dissertation $A b$ stracts International. 1989; 50/11-B. 5367.

57. Siegler I, Welsh K, Dawson D, Fillenbaum G, Earl N, Kaplan E, Clark C: Ratings of personality changes in patients being evaluated for memory disorders. Alzheimer's Disease and Associated Disorders. $1991 ; 5(4), 240-250$.

58. Strauss M, Pasupathi M, Chaterjee A: Concordance between observers in descriptions of personality change in Alzheimer's disease. Psychology and Aging. 1993; 8, 475-480.

59. Dawson P, Reid DW: Behavioral dimensions of patients at risk for wandering. Gerontologist. 1987; 27, 104-107.

60. Pearlson G, Ross, Lohr W, Rovner B, Chase G, Folstein M: Association between family history of affective disorder and the depressive syndrome of Alzheimer's disease. American Journal of Psychiatry. 1990; 147, 452-456.

61. Rovner B, Broadhead J, Spenser M, Carson K, Folstein M: Depression and Alzheimer's disease. American Journal of Psychiatry. $1990 ; 146,350-353$.

62. Hamel M, Pushkar D, Gold D, Andres D, Reis M, Dastoor D, Grauer H, Bergman H: Predictors and consequences of aggressive behavior by community-based dementia patients. The Gerontologist. 1990; 30(2), 206-211.

63. Meddaugh D: Reactance: Understanding aggressive behavior in long-term care. Journal of Psychosocial Nursing and Mental Health Services. 1990; 28(4), 28-33.

64. Ryden M: Aggressive behavior in persons with dementia who live 
in the community. Alzheimer's Disease and Associated Disorders. $1988 ; 2(4), 342-355$.

65. Headey B, Wearing A: Personality, life events, and subjective well-being: toward a dynamic equilibrium model. Journal of Personality and Social Psychology. 1989; 57(4), 731-739.

66. Fergusson D, Horwood L: Vulnerability to life events exposure. Psychological Medicine 1987; 17.739-749.

67. Magnus K, Dieni E, Fujita F, Pavot W: Extroversion and neuroticism as predictors of objective life events: A longitudinal analysis. Journal of Personality and Social Psychology. 1993; 65(5), 10461053.

68. Benca RM, Obermeyer WH, Thisted RA, Gillin JC: Sleep and psychiatric disorders: A meta-analysis. Archives of General Psychiatry. 1992; 49(8), 651-658.

69. Prinz PN, Peskind ER, Vitaliano PP, Raskind MA, Eisdorfer C, Zemcuznikov N, Gerber CJ: Changes in the sleep-waking of nondemented and demented elderly subjects. Journal of the American Geriatric Society. 1982a; 30(2), 86-93.

70. Prinz PN, Vitaliano PP, Bokan J, Raskind MA, Peskind E, Gerber CJ: Sleep, EEG and mental function changes in senile dementia of the Alzheimer's type. Neurobiology of Aging. 1982; 3(4), 361-370.

71. Vitiello MV, Prinz PN, Williams DE, Frommlet MS, Reis RK: Sleep disturbances in patients with mild-stage Alzheimer's disease. Journal of Gerontology. 1990; 45(4), M131-138.

72. Coleman RM, Miles LE, Guilleminault CC, Zarcone VP, van den Hoad J, Dement WC: Sleep-wake disorders in the elderly: polysomnographic analysis. Journal of the American Geriatric Society. 1981; 29 (7), 289-296.

73. Roehrs T, Zorick F, Sicklesteel J, Wittig R, Roth T: Age-related sleep-wake disorders at a sleep disorder center. Journal of the American Geriatrics Society. 1983; 31(6), 364-370.

74. Rosenthal L, Roehrs TA, Roth T: The Sleep Wake Activity Inventory: a self report measure of daytime sleepiness. Biological Psychiatry. 1992; 34(11), 810-820.

75. Bliwise DL, JA, Tinglenberg JR, Dement WC: Sleep apnea in Alzheimer's disease. Neurobiology of Aging. 1989; 10(4), 343-346.

76. Erkinjuntti T, Partinen M, Sulkava R, Palomaki H, Tilvis R: Snoring and dementia. Age and Aging. 1987; 16(5), 305-310.
77. Bates MM: The etiology and maintenance of dependency in the elderly: Three phrases of operant research. Behavior Therapy. 1988; $19,301-319$.

78. Hall GR, Buckwalter KC: Progressively lowered stress threshold: a conceptual model for care of adults with Alzheimer's disease. Archives of Psychiatric Nursing. 1987; 1, 399-406.

79. Evans LK: Sundown syndrome in institutionalized elderly. Journal of the American Geriatrics Society. 1987; 35, 101-108.

80. Lovell B, Ancoli-Israel S, Gevirtz R: Effect of bright light treatment on agitated behavior in institutionalized elderly subjects. Psychiatry Research. 1995; 57, 7-12.

81. Mishima K, Okawa M, Hishikawa Y, Hosumi S, Hori H, Takahashi $\mathrm{K}$ : Morning bright light therapy for sleep and behavior disorders in elderly patients with dementia. Acta Psychiatric Scandinavia. 1994; 89(1), 1-7.

82. Cohen-Mansfield J, Werner P, Marx M: Screaming in nursing home residents. Journal of the American Geriatrics Society. 1990c; 38, 785-792.

83. Cohen-Mansfield J, Marx M: The social network of the agitated nursing home resident. Research on Aging. 1992; 14 (1) 110-123.

84. Kolanowski A, Hurwitz S, Taylor L, Evans L, Strumpf N: Contextual factors associated with disturbing behaviors in institutionalized elders. Nursing Research. 1994; 43(73-7g).

85. Roberts BL, Algase DL: Victims of Alzheimer's disease and the environment. Nursing Clinics of North America. 1988; 23(1), 83-93. 86. Haxby J, Duara R, Grady C, Cutler N, Rapoport S: Relations between neuropsychobiological and cerebral asymmetrical in early Alzheimer's disease. Journal of Cerebral Blood Flow and Metabolism. 1985; 5, 193-200.

87. Reisberg D, Ferris S, Armand R, deLeon M, Schenk M, Buttinger C, Borsteen J: Functional staging of dementia of the Alzheimer's type Annals of the New York Academy of Sciences. 1984; 435, 481-483.

An earlier version of this paper was presented at the 48th Annual Scientific Meeting of the Gerontological Society of America in Los Angeles, CA in November, 1995. 